\title{
An emerging treatment option for glaucoma: Rho kinase inhibitors
}

This article was published in the following Dove Press journal:

Clinical Ophthalmology

9 May 2014

Number of times this article has been viewed

\section{Sean K Wang' \\ Robert T Chang ${ }^{2}$}

'Stanford University, Stanford, CA, USA; ${ }^{2}$ Stanford University School of Medicine, Stanford, CA, USA
Correspondence: Robert T Chang Byers Eye Institute at Stanford, 2452 Watson Ct, Palo Alto, CA 94303, USA

Email viroptic@gmail.com
Abstract: Rho kinase (ROCK) inhibitors are a novel potential class of glaucoma therapeutics with multiple compounds currently in Phase II and III US Food and Drug Administration trials in the United States. These selective agents work by relaxing the trabecular meshwork through inhibition of the actin cytoskeleton contractile tone of smooth muscle. This results in increased aqueous outflow directly through the trabecular meshwork, achieving lower intraocular pressures in a range similar to prostaglandins. There are also animal studies indicating that ROCK inhibitors may improve blood flow to the optic nerve, increase ganglion cell survival, and reduce bleb scarring in glaucoma surgery. Given the multiple beneficial effects for glaucoma patients, ROCK inhibitors are certainly a highly anticipated emerging treatment option for glaucoma.

Keywords: ROCK inhibitors, actin cytoskeleton, aqueous dynamics review

\section{Introduction}

Glaucoma is an optic neuropathy in which at least one eye has accelerated ganglion cell death characterized by excavated cupping appearance of the optic nerve with progressive thinning of retinal nerve fiber layer tissue and corresponding subsequent visual field loss. As the leading cause of irreversible blindness worldwide, the disease affected more than 60.5 million individuals in 2010, an estimate extrapolated from multiple population-based surveys, and is projected to reach 79.6 million by the year $2020 .^{1,2}$ Because of its initial asymptomatic nature, especially in the early stages, glaucoma may remain undiagnosed in up to half of total cases in developed nations and even more in regions of the developing world, where the incidence may be higher at older age and with certain ethnicities. ${ }^{3,4}$ Historically, intraocular pressure (IOP) has been recognized as the primary modifiable risk factor. It is now accepted as a continuous, fluctuating variable. The goal of contemporary therapy is to reduce IOP to a range that preserves structural and functional testing results. ${ }^{5-7}$ Present strategies to slow the rate of glaucomatous progression all focus on lowering IOP, as other strategies such as neuroprotection have not met their clinical trial endpoints. At this time, IOP can be lowered by affecting inflow and outflow via pharmacologic agents (five current classes include prostaglandin analogs, beta-blockers, carbonic anhydrase inhibitors, sympathomimetics, and miotics), laser trabeculoplasty, and incisional surgery, which can be divided into standard filtration surgery or various newer minimally invasive procedures. ${ }^{8-11}$ Current research is also looking beyond lowering IOP, with a focus on protecting or regenerating the optic nerve as well as novel targets to decrease inflow or increase outflow including small interfering RNA, cytoskeleton agents, cannabinoids, adenosine/serotonin/dopamine receptor ligands, nitric oxide/carbon monoxide system modulators, and hydroxysteroid dehydrogenase inhibitors. ${ }^{12}$ 


\section{Aqueous dynamics review}

To understand new pharmacologic targets for IOP reduction, it is best to review normal aqueous humor dynamics. IOP is a complex homeostatic process, but it can be simplified by comparing the rate of aqueous humor formation inside the posterior chamber against the rate of aqueous humor exiting the anterior chamber. Aqueous humor formation occurs in the ciliary epithelium lining the ciliary processes of the ciliary body and is created through a combination of passive diffusion and ultrafiltration, with the majority of aqueous derived from active secretion via selective transcellular movement of molecules mediated by protein transporters. ${ }^{13}$ Thus, enzymes and receptors found in the pigmented and nonpigmented ciliary epithelium are current drug targets to reduce aqueous humor production. How exactly the eye detects pressure to affect the rate of aqueous formation is not known, although circadian variation and maintenance of stable IOP indicates adjustable control over inflow and outflow until compromised in the disease state. ${ }^{14}$

Once produced, aqueous makes its way from the posterior chamber to the anterior chamber and is traditionally believed to drain out of the eye through either the conventional pathway via the trabecular meshwork (TM) or the unconventional pathway via the uveoscleral route. ${ }^{13}$ However, the exact route is not known, as there is no reliable real-time observation method. The downstream conventional pathway drains into Schlemm's canal, collector channels, and eventually the episcleral venous system. Outflow resistance has been classically associated with the juxtacanalicular portion of TM mediated through extracellular matrix, but resistance may also be mediated by the permeability of the endothelial cell lining of Schlemm's canal. ${ }^{15,16}$ The uveoscleral unconventional pathway empties into spaces of the ciliary muscle and into the suprachoroidal space. Existing pharmacologic agents target both outflow pathways, and newer surgical devices currently under development are capitalizing on the suprachoroidal drainage space. More recently, a novel "uveolymphatic" pathway in animal eyes has also been identified using quantum dot injection of nanotracers. ${ }^{17}$ Rather than continuous outflow, in vivo imaging studies of trabecular meshwork have now revealed a pulsatile motion of flow into the venous system, synchronized with cardiac pulse, blinking, and eye movement. ${ }^{18,19}$

Under glaucomatous conditions, elevation of IOP arises in part as a consequence of impaired TM function. Some studies suggest glycosaminoglycans or other mucopolysaccharide deposits are responsible for impaired outflow resistance, in addition to the influence of the iris and ciliary muscle contraction affecting the drainage of the TM and Schlemm's canal. ${ }^{13}$ Anatomically, the TM is comprised of a spongy connective tissue containing collagen and elastin fibers surrounded by endothelial-like trabecular cells, or trabeculocytes, which rest on a basement membrane. Cells of the TM have been reported to display smooth muscle-like properties including contractility, electromechanical characteristics, and expression of smooth muscle-specific actin and myosin, all of which may facilitate dynamic restructuring and result in disease as the cell population declines with age. ${ }^{20,21}$ Other factors implicated in glaucoma and the regulation of aqueous outflow include cell adhesive interactions, extracellular matrix proteins, and the cytoskeletal assembly. ${ }^{22-24}$ In particular, transforming growth factor $\beta$ in human TM cells, which has been found to be higher in eyes with glaucoma, has been shown to switch cell-cell adhesions, hinting that this signal may induce some of the biomechanical alterations found in glaucomatous TM tissue. ${ }^{25}$ Nonetheless, the role of transforming growth factor $\beta$ in glaucoma development and progression has yet to be directly established, limiting its practicality as a biomarker or as a therapeutic target. Elevated IOP has also been correlated with higher concentrations in the aqueous humor of matrix metalloproteinases, a set of enzymes that cleave and remodel the extracellular matrix. As modulators of TM architecture, matrix metalloproteinases are likely important in upholding IOP homeostasis. However, the behavior of these enzymes in human eyes is still unclear and requires further investigation. ${ }^{26}$ Finally, endothelin 1 , also found to be higher in glaucomatous eyes, is a ligand in TM cells that mediates actin cytoskeleton reorganization and cell contraction to adjust aqueous outflow. Recognized as one of the most potent vasoactive peptides, endothelin 1 is also a major upstream activator of the Rho and Rho-associated protein kinase signaling pathway, which is thought to be involved in actomyosin assembly, cell adhesive interactions, and the expression of extracellular matrix (ECM) proteins and cytokines in TM cells. ${ }^{27}$

This review concentrates on one part of this complex, multifactorial inflow and outflow mechanism of IOP regulation, with a focus on the cellular mechanisms of ECM turnover and contractile activity in relation to Rho kinase. There exists a general consensus that Rho kinase inhibitors alter actomyosin activity in the TM while exerting minimal toxic effects on the eye and, therefore, may be of therapeutic value in the reduction of IOP via the conventional pathway. ${ }^{28}$ Much translational work has been carried out to develop this novel glaucoma medication class, Rho kinase inhibitors, with multiple clinical trials in progress.

\section{Rho and Rho-associated protein kinases}

The Rho family consists of three small guanosine triphosphate (GTP)-binding proteins (RhoA, RhoB, RhoC), which 
regulate aspects of cell shape, motility, proliferation, and apoptosis throughout the body. ${ }^{29}$ On activation by binding to GTP, Rho activates its effector molecules (Rho kinase ROCK1 and 2), which signal downstream molecules to polymerize actin fibers in the cardiovascular, pulmonary, and renal systems. ${ }^{30,31}$ Rho GTPases were first hypothesized to function in aqueous humor outflow in 2001 because of their expression in TM, with the ability to induce calcium-sensitization in smooth muscle contraction in rabbit eyes. ${ }^{32,33}$ Since then, significantly elevated levels of RhoA have been detected by immunostaining in the optic nerve head of glaucomatous eyes compared with agematched controls, reinforcing the association of Rho proteins and glaucoma pathophysiology. ${ }^{34}$

ROCKs are serine/threonine kinases that regulate smooth muscle contraction in which selective ROCK inhibitors could increase aqueous humor drainage through the TM, leading to a decrease in IOP. ${ }^{35}$ In mammals, ROCKs exist as two isoforms: ROCK1, which is located on chromosome 18 and contains 1,354 amino acids, ${ }^{36,37}$ and ROCK2, which is located on chromosome 12 and encodes a 1,388-amino acid product. ${ }^{38,39}$ Overall, ROCK1 and ROCK2 share $65 \%$ homology in amino acid sequence with $92 \%$ homology in their kinase domains. ${ }^{30}$ In humans, ROCK 1 and ROCK2 tend to be expressed in the majority of tissues, including human TM and ciliary muscle cells. ${ }^{36}$ Structurally, ROCKs are composed of three major domains: an N-terminal kinase domain that phosphorylates protein targets, a C-terminal autoinhibitory domain that limits kinase activity via intramolecular interactions, and a coiled-coil Rho-binding domain that appears to facilitate the switch from the inactive to active conformation. ${ }^{30,40}$ On binding to Rho, the catalytic activity of ROCKs is moderately enhanced, although activation of the kinase can also occur in response to lipids such as arachidonic acid. ${ }^{36,41}$ This may be important in linking cholesterollowering statin use and reduced risk for glaucoma.

Among other substrate targets, ROCKs inhibit myosin light chain phosphatase by phosphorylating the myosinbinding subunit, thereby mediating actin cytoskeletal changes and inducing vasoconstriction. ${ }^{42}$ Analogously, ROCKs activate LIM kinases via phosphorylation, which in turn stabilize filamentous actin and reduce the occurrence of cell migration..$^{29}$ The exact molecular mechanism of depolymerization of filamentous actin leading to increased outflow has not been fully worked out, but it has been hypothesized that wider empty spaces in the juxtacanalicular region and increased vacuoles in endothelial cells improve outflow volume. Other targets of ROCKs include CPI-17 (a phosphoprotein phosphatase inhibitor), sodium/hydrogen exchange protein, adducin, and the ezrin/radixin/moesin family of actin-binding proteins. ${ }^{35}$ Thus, ROCKs appear to have several actin cytoskeletal-related targets that directly affect the contractile properties of TM outflow tissue (Figure 1). Loss of ROCK function has previously been associated with

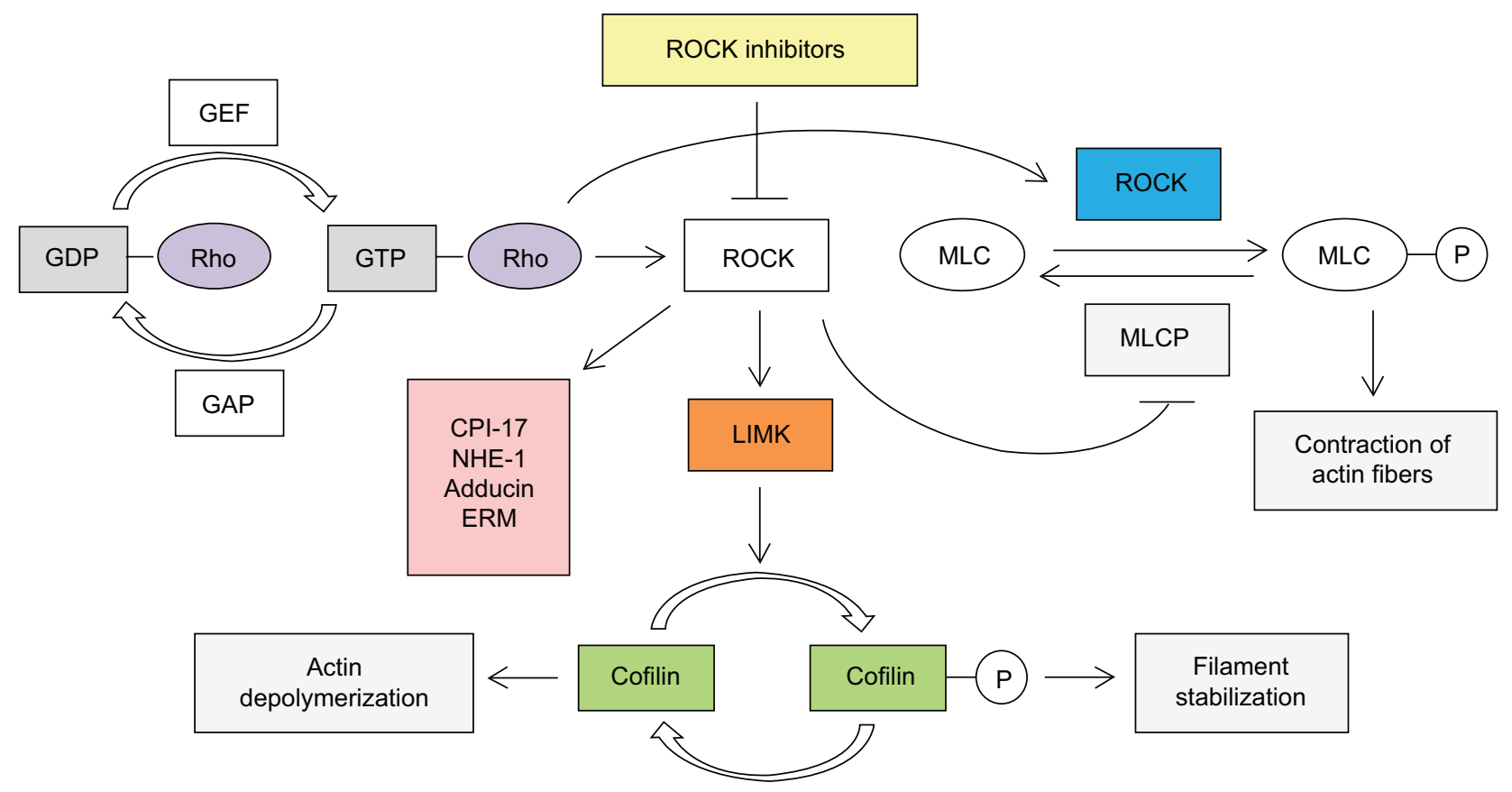

Figure I Role and regulation of Rho kinase.

Abbreviations: ROCK, Rho kinase; MLC, myosin light chain; MLCP, myosin light chain phosphatase. 
micromechanical relaxation of cells and disassembly of stress fibers and focal adhesion complexes. ${ }^{36,42}$ In contrast, overexpression of ROCK activity is observed in tumor metastasis, with loss of cytoskeletal regulation, and may promote tumor invasion. ${ }^{43,44}$ Therefore, ROCKs may play a role in further elucidating glaucoma pathogenesis as well as ROCK inhibitors becoming a new category in glaucoma therapeutics.

\section{ROCK inhibitors and IOP}

Multiple studies have indicated that ROCK and Rho GTPase inhibitors can increase aqueous humor drainage in TM tissue, leading to a reduction in IOP. ${ }^{35,45,46}$ As defined by current models, ROCK inhibitors induce reversible modifications to cell morphology and cell interactions in the eye that facilitate greater outflow of aqueous humor and, ultimately, result in a lower IOP. According to perfusion studies performed by Rao et $\mathrm{al}^{47}$ using enucleated porcine eyes, 10-100 $\mu \mathrm{M}$ ROCK inhibitor Y-27632 increased aqueous humor outflow through cells of the TM by up to $80 \%$ in a dose-dependent manner. Compared with control specimens, drug-treated samples exhibited a widening of the extracellular spaces and juxtacanalicular tissue, which resulted in an overall distended appearance. Moreover, on isolation of TM tissue from eyes perfused with the ROCK inhibitor, a decrease in myosin light chain phosphorylation was observed, suggesting that the changes in cell morphology and aqueous outflow were influenced by actomyosin cytoskeletal organization. ${ }^{47}$

Previous experiments using a spectrum of ROCK inhibitors have correlated morphological changes in the TM and juxtacanalicular regions with rapid and long-lasting IOP reductions active within 30 minutes of administration and lasting up to 12 hours. ${ }^{48-50}$ In a seminal paper in 2001 , Honjo et al measured the IOP and outflow facility of 18 rabbit eyes in vitro before and after topical, intracameral, or intravitreal administration of Y-27632. Within a 3-hour period, topical and intracameral delivery of Y-27632 decreased IOP by $30 \%$ and produced a two fold increase in trabecular outflow, thereby linking the observed IOP-lowering effects to altered TM cell behavior. ${ }^{33}$ In live rabbits, topical administration of two other ROCK inhibitors, H-1152P and HA-1077, both produced dose-dependent declines in IOP. For H-1152P, a maximum IOP-lowering effect of $7.2 \mathrm{mmHg}(46.1 \%)$ versus control eyes was observed in normotensive animals at $28 \mathrm{mM}$ dosing. ${ }^{51}$ Likewise, treatment of 18 ocular hypertensive rabbits with $3 \mathrm{mM}$ HA-1077 lowered IOP by an average of $5.3 \mathrm{mmHg}(46.4 \%) .{ }^{52}$ For both of these models, peak reductions were comparable with those of the antiglaucoma drug latanoprost, which decreased IOP by $22.6 \%$ and $40.3 \%$, respectively, in normotensive and ocular hypertensive rabbit eyes. ${ }^{53}$
In other animal models, ROCK inhibitors have similarly induced structural changes associated with decreased IOP levels. As demonstrated by Lu et al in $2008,{ }^{54}$ perfusion of seven bovine eyes with Y-27632 resulted in a 58\% enhancement, on average, in outflow activity and significant gains in effective filtration area compared with controls, as measured by fluorescent microspheres. In addition, after treatment with the inhibitor, regions of the juxtacanalicular connective tissue appeared to become more prevalent, supporting the notion that TM and juxtacanalicular cells were responsible for the increase in aqueous outflow facility. ${ }^{54}$ These findings have since been corroborated in mouse and monkey eyes by analogous studies observing IOP reductions with ROCK inhibitor Y-39983. ${ }^{55-57}$ Based on the consistent behavior of these compounds across multiple animal models as IOP-lowering agents, translational work began as companies started human trials.

\section{Other applications of Rho kinase inhibitors in glaucoma}

Reportedly, ROCK inhibitors may have uses in glaucoma management other than lowering IOP. Animal studies have demonstrated increased ocular blood flow as well as potential neuroprotective effects, and ROCK inhibitors may also have the potential to reduce postoperative scarring during glaucoma-filtering surgery. ${ }^{48,58-63}$ In a 2011 paper by Tokushige et $a^{56}$ a $0.05 \%$ solution of Y-39983 was topically administered to the eyes of six live rabbits. For each of these animals, blood flow in the optic nerve head was significantly improved after treatment, presumably through the relaxation of vascular endothelial smooth muscle. ${ }^{58}$ Similarly, in 2011 , Sugiyama et $\mathrm{al}^{48}$ showed that both intravenous and topical doses of Fasudil (Asahi Kasei Corporation, Tokyo, Japan), a ROCK inhibitor, prevented impairment of optic nerve blood flow by a known nitric oxide synthase inhibitor in rabbits, thereby reinforcing the ability of ROCK inhibitors to mediate normal blood flow in the eye. ${ }^{48}$ Considering the theorized role of disrupted ocular blood flow in glaucoma pathogenesis, and especially in patients with normal-tension glaucoma, ${ }^{59}$ these data hint at an additional therapeutic advantage conferred by ROCK inhibitors.

Several investigators have studied ROCK inhibitor use with glaucoma filtering surgery, where it may also act to prevent postoperative scarring, one of the most common causes of failed glaucoma filtering surgery. As described by Meyerter-Vehn et al in 2006, ${ }^{60}$ activity of Y-27632 in human tendon fibroblasts blocked the assembly and contraction of transforming growth factor $\beta$-induced stress fibers normally implicated in myofibroblast transdifferentiation. Because a crucial step in 
the wound-healing process is the transformation of fibroblasts to myofibroblasts, this finding implies that ROCK inhibitors may reduce postoperative scarring after glaucoma filtration surgery. ${ }^{60}$ Such a model is further supported by in vivo experiments in rabbits, in which topical instillation of $10 \mathrm{mM}$ Y-27632 inhibited fibroproliferation and collagen deposition after glaucoma filtration surgery, leading to prolonged survival of the postoperative bleb and better surgical outcome. ${ }^{61}$

Finally, ROCK inhibitors appear to influence neuron survival and axon regeneration, as demonstrated by the neuroprotective effects of inhibitors for both Rho and ROCK in animal cells. ${ }^{35}$ In 2004, rat studies performed by Kitaoka et $\mathrm{al}^{62}$ found that intravitreal injection of animals with $10^{-5} \mathrm{M}$ Fasudil (Asahi Kasei Corporation) protected against glutamate-related excitotoxicity in the retina and better preserved cells of the ganglion cell layer on exposure to N-methyl-D-aspartate. ${ }^{62}$ Moreover, as reported by Tokushige et $\mathrm{al}^{56}$ rat retinal ganglion cells treated with 10 or $100 \mu \mathrm{M}$ Y-39983 exhibited increased axon regeneration, first under culture conditions and, subsequently, in vivo compared with saline-treated animals. ${ }^{58}$ Sagawa et al in $2007,{ }^{63}$ observed that immediately after crushing the optic nerve in adult cats, injection of $10 \mu \mathrm{M}$ Y-39983, but not control saline, into the vitreous was capable of inducing the crushed axons to regenerate and pass over the site of damage. ${ }^{63}$ Thus, ROCK inhibitors may possess therapeutic potential for axonal regeneration of ganglion cells in the treatment of diseases with degenerating axons such as glaucoma.

\section{Clinical trials of Rho kinase inhibitors}

To date, only one ROCK inhibitor, Fasudil (HA-1077; Asahi Kasei Corporation), has been marketed for clinical use in cerebral vasospasm. ${ }^{64}$ Given the risks associated with developing effective kinase inhibitors for a chronic condition such as glaucoma, current clinical studies have focused on drug candidates that are not only potent but also highly selective over other protein kinases. ${ }^{65}$ As of February 2014, four ROCK inhibitor-based drugs were actively undergoing human clinical trials (Table 1).

Among the farthest along in the clinical trial process is K-115, developed by Kowa (Aichi, Japan). During Phase I trials, 50 healthy volunteers were treated with placebo or $\mathrm{K}-115$ in concentrations of $0.05 \%, 0.1 \%, 0.2 \%, 0.4 \%$, and $0.8 \%$ in a stepwise manner, either as a single instillation or repeated twice daily for 7 days. ${ }^{66}$ Mean IOP reduction of up to $4.3 \mathrm{mmHg}$ for the highest concentration of treatment was observed 1-2 hours after instillation. Regarding adverse effects, more than half of participants treated with K-115 showed slight to mild conjunctival hyperemia, which spontaneously resolved for all cases within several hours. ${ }^{66}$ During Phase II trials, dose-response treatment of 210 patients with primary open-angle glaucoma or ocular hypertension resulted in a mean IOP reduction of $4.5 \mathrm{mmHg}$ for $0.4 \% \mathrm{~K}-115$ after 2 hours. Outcomes of the drug at this concentration were statistically significant at all times, leading Tanihara et al to recommend twice-daily administration of $0.4 \% \mathrm{~K}-115$ as the optimal dose to control IOP. ${ }^{67}$

Another promising ROCK inhibitor designed for glaucoma therapy is AR-13324, developed by Aerie Pharmaceuticals Inc., (Research Triangle Park, NC, USA) and expected to commence Phase III clinical trials soon. Characterized as "dual action", AR-13324 acts to lower IOP by enhancing fluid outflow through the trabecular pathway while simultaneously decreasing fluid inflow to the eye. In rabbits, oncedaily treatment with $0.04 \%$ AR-13324 produced maximal mean IOP reductions of up to $7.1 \mathrm{mmHg}(27 \%)$ at 4 hours after dosing. Likewise, in monkeys, the same concentration of AR-13324 reduced mean IOP after 3 days of treatment by $7.5 \mathrm{mmHg}(37 \%), 7.2 \mathrm{mmHg}(36 \%)$, and $7.5 \mathrm{mmHg}$ (37\%), respectively, at 4,8 , and 24 hours after dosing. ${ }^{68}$ In June 2013, AR-13324 successfully completed its Phase IIb

Table I Clinical trials of Rho kinase inhibitors in glaucoma

\begin{tabular}{lll}
\hline Compound & Organization & Highest development phase \\
\hline AMA0076 & Amakem, Diepenbeek, Belgium & Phase II \\
AR-12286* & Aerie Pharmaceuticals Inc., Research Triangle Park, NC, USA & Phase II \\
AR-13324 & Aerie Pharmaceuticals Inc. & Phase III \\
ATS907* & Altheos Inc., South San Francisco, CA, USA & Phase II \\
DE-104* & Santen-Ube, Osaka City and Ube City, Japan & Phase II \\
INS-II5644* & Merck, Whitehouse Station, NJ, USA & Phase I \\
INS-II 17548* & Merck & Phase I \\
K-II5 & Kowa, Aichi, Japan & Phase III \\
PG324 & Aerie Pharmaceuticals Inc. & Phase II \\
Y-39983; RKI-983; SNJ-1656* & Senju, Tokyo, Japan; and Novartis Pharmaceuticals, Basel, Switzerland & Phase II \\
\hline
\end{tabular}

Note: *Compound development discontinued. 
trial, demonstrating that once-daily administration could significantly lower IOP by $5.7-6.2 \mathrm{mmHg}$ in patients with elevated IOP.

Beyond "dual action", Aerie Pharmaceuticals Inc., has also proposed a "triple-action" therapy combining AR-13324 with latanoprost, the most frequently prescribed glaucoma medicine. Named PG324, the drug is presently undergoing Phase II trials and aims to become the first glaucoma eye drop, dosed once daily, employing three distinct mechanisms to lower IOP. A 28-day Phase IIb clinical trial for PG324 including approximately 300 patients is expected to begin in the first quarter of 2014, with results anticipated by midyear.

Last, the lead compound of Amakem (Diepenbeek, Belgium), AMA0076, completed its Phase I trials in 2013. ${ }^{69}$ Applied as eye drops, AMA0076 is unique in that outside the aqueous humor, the drug is rapidly converted into an inactive form that can subsequently be eliminated from the body, potentially reducing off-target activity and adverse effects such as hyperemia. Although findings from AMA0076's clinical trials have yet to be published in the literature, company reports indicate that the compound achieved a mean IOP reduction of $3.7 \mathrm{mmHg}$ with little to no observation of conjunctival hyperemia.

It is important to recognize that although many promising trials for ROCK inhibitor compounds are presently underway, a substantial number of candidates have already failed. Despite early success in animal studies and Phase I clinical trials, ${ }^{56,70}$ development of Y-39983, synonymous with RKI983 and SNJ-1656, was terminated by Senju (Tokyo, Japan) and Novartis Pharmaceuticals (Basel, Switzerland) during Phase II trials. Similarly, progress on Aerie Pharmaceuticals Inc., AR-12286 was abandoned in June 2013 because of an inability to maintain significant IOP reduction over time. From Merck (Whitehouse Station, NJ, USA), both INS117548 and INS-115644 were discontinued during the Phase I stage, most likely because of safety and tolerability concerns in human patients. In late 2010, Santen-Ube, Osaka City and Ube City, Japan, also abandoned its ROCK inhibitor, DE-104, after a Phase II trial fell short of meeting the primary endpoint. ${ }^{71}$ Finally, ATS907, a topically administered drug designed by Altheos Inc., South San Francisco, CA, USA, exhibited initially favorable outcomes because of its wide therapeutic index and rapid conversion in the eye into a more potent and selective metabolite. ${ }^{72}$ However, after failed Phase II testing in 2012, the company ultimately closed down, underscoring the fact that not all ROCK inhibitors have demonstrated clinical efficacy in treating glaucoma without adverse effects.

\section{Therapeutic risks of Rho kinase inhibitors}

Of the four ROCK inhibitor-based drugs continuing clinical trials, all seem to have an optimistic safety profile, as indicated by Phase I results. The most common noted adverse effect is conjunctival hyperemia resulting from vasodilation of conjunctival vessels. ${ }^{70}$ No conjunctival hemorrhage was seen, but it has been noted in animal studies. Still, given the list of failed candidates discussed in this review, ROCK inhibitors are not without risk. Because ROCKs belong to a class of serine/threonine kinases, higher concentrations of these inhibitors may affect other protein kinases in the body, including protein kinase $\mathrm{A}$, protein kinase $\mathrm{C}$, and myosin light chain kinase, among others. ${ }^{42,50}$ Therefore, dosing of ROCK inhibitors must be carefully designed to minimize unintended cross-reactivity with alternate kinase pathways.

On a systemic level, ROCK inhibition is known to lower blood pressure and vascular resistance, thus bearing potential consequences in case of unwanted systemic exposure. ${ }^{55}$ To avoid these risks in the context of glaucoma, drugs such as AMA0076 have been developed with the objective of remaining active only within the aqueous humor. From ongoing clinical trials, it is also evident that the major adverse effect of most, if not all, ROCK inhibitors is ocular hyperemia, most likely because of the pharmacology of these agents as vasodilators. ${ }^{66,69}$ Considering the spontaneous resolution of adverse hyperemia typically within several hours, one option in future practice may be to have the drug administered at bedtime to mitigate any negative appearance. Notably, Arnold et al in $2013,,^{73}$ observed that on concurrent administration, ROCK inhibition reduced the intraocular penetration of betablocker timolol maleate, presumably because of increased systemic elimination through the conjunctival vasculature. ${ }^{73}$ In view of the much-anticipated release of a ROCK inhibitor for glaucoma treatment, clinicians should be wary of this and similar confounding interactions, particularly in the prescribing of new drug regimens to address the disease.

\section{Conclusion}

As a novel class of pharmacological agents to slow down glaucomatous progression, ROCK inhibitors have been reported to offer at least four distinct applications relevant to glaucoma management, including significant IOP-lowering effects, improvement in ocular blood flow, inhibition of postoperative scarring, and promotion of retinal ganglion cell survival and axon regeneration. In contrast to the wide variety of glaucoma drugs today, which, in general, reduce IOP by suppressing aqueous humor production, ROCK inhibitors 
appear to facilitate greater aqueous outflow by mediating actomyosin regulation, thereby ultimately lowering IOP. Over the past decade, a considerable number of ROCK inhibitor candidates have failed during clinical testing, most often because of insufficient efficacy or unforeseen adverse effects such as hyperemia. Nonetheless, four ROCK inhibitor-based drugs (K-115, AR-13324, PG324, AMA0076) have continued to show promise as future glaucoma therapeutics. Ongoing clinical trials for each of these compounds are crucial to the development of better IOP-lowering therapies and may initiate the next major advancement in the treatment of glaucoma.

\section{Disclosure}

The authors report no conflicts of interest in this work.

\section{References}

1. Varma R, Lee PP, Goldberg I, Kotak S. An assessment of the health and economic burdens of glaucoma. Am J Ophthalmol. 2011; 152(4):515-522.

2. Quigley HA, Broman AT. The number of people with glaucoma worldwide in 2010 and 2020. Br J Ophthalmol. 2006;90(3):262-267.

3. Quigley HA. Glaucoma. Lancet. 2011;377(9774):1367-1377.

4. Budenz DL, Barton K, Whiteside-de Vos J, et al; Tema Eye Survey Study Group. Prevalence of glaucoma in an urban West African population: the Tema Eye Survey. JAMA Ophthalmol. 2013;131(5):651-658.

5. Kass MA, Heuer DK, Higginbotham EJ, et al. The Ocular Hypertension Treatment Study: a randomized trial determines that topical ocular hypotensive medication delays or prevents the onset of primary openangle glaucoma. Arch Ophthalmol. 2002;120(6):701-713.

6. Crawley L, Zamir SM, Cordeiro MF, Guo L. Clinical options for the reduction of elevated intraocular pressure. Ophthalmol Eye Dis. 2012;4:43-64.

7. Musch DC, Gillespie BW, Niziol LM, Lichter PR, Varma R; CIGTS Study Group. Intraocular pressure control and long-term visual field loss in the Collaborative Initial Glaucoma Treatment Study. Ophthalmology. 2011;118(9):1766-1773.

8. Marquis RE, Whitson JT. Management of glaucoma: focus on pharmacological therapy. Drugs Aging. 2005;22(1):1-21.

9. Samples JR, Singh K, Lin SC, et al. Laser trabeculoplasty for openangle glaucoma: a report by the american academy of ophthalmology. Ophthalmology. 2011;118(11):2296-2302.

10. Gedde SJ, Schiffman JC, Feuer WJ, Herndon LW, Brandt JD, Budenz DL; Tube versus Trabeculectomy Study Group. Treatment outcomes in the Tube Versus Trabeculectomy (TVT) study after five years of follow-up. Am J Ophthalmol. 2012;153(5):789-803.

11. Francis BA, Singh K, Lin SC, et al. Novel glaucoma procedures: a report by the American Academy of Ophthalmology. Ophthalmology. 2011;118(7):1466-1480.

12. Bucolo C, Salomone S, Drago F, Reibaldi M, Longo A, Uva MG. Pharmacological management of ocular hypertension: current approaches and future prospective. Curr Opin Pharmacol. 2013;13(1):50-55.

13. Goel M, Picciani RG, Lee RK, Bhattacharya SK. Aqueous humor dynamics: a review. Open Ophthalmol J. 2010;4:52-59.

14. Nau CB, Malihi M, McLaren JW, Hodge DO, Sit AJ. Circadian Variation of Aqueous Humor Dynamics in Older Healthy Adults. Invest Ophthalmol Vis Sci. Epub 2013 Sep 26.

15. Zhou EH, Krishnan R, Stamer WD, et al. Mechanical responsiveness of the endothelial cell of Schlemm's canal: scope, variability and its potential role in controlling aqueous humour outflow. J R Soc Interface. 2012;9(71):1144-1155.

16. Keller KE, Acott TS. The Juxtacanalicular Region of Ocular Trabecular Meshwork: A Tissue with a Unique Extracellular Matrix and Specialized Function. J Ocul Biol. 2013;1(1):3.
17. Tam AL, Gupta N, Zhang Z, Yücel YH. Latanoprost Stimulates Ocular Lymphatic Drainage: An In Vivo Nanotracer Study. Transl Vis Sci Technol. 2013;2(5):3.

18. Li P, Shen TT, Johnstone M, Wang RK. Pulsatile motion of the trabecular meshwork in healthy human subjects quantified by phase-sensitive optical coherence tomography. Biomed Opt Express. 2013;4(10): 2051-2065.

19. Johnstone M, Martin E, Jamil A. Pulsatile flow into the aqueous veins: manifestations in normal and glaucomatous eyes. Exp Eye Res. 2011;92(5):318-327.

20. Epstein DL, Rowlette LL, Roberts BC. Acto-myosin drug effects and aqueous outflow function. Invest Ophthalmol Vis Sci. 1999;40(1):74-81.

21. Rao PV, Deng P, Maddala R, Epstein DL, Li CY, Shimokawa H. Expression of dominant negative Rho-binding domain of Rho-kinase in organ cultured human eye anterior segments increases aqueous humor outflow. Mol Vis. 2005;11:288-297.

22. Gabelt BT, Kaufman PL. Changes in aqueous humor dynamics with age and glaucoma. Prog Retin Eye Res. 2005;24(5):612-637.

23. Rosenthal R, Choritz L, Schlott S, et al. Effects of ML-7 and Y-27632 on carbachol- and endothelin-1-induced contraction of bovine trabecular meshwork. Exp Eye Res. 2005;80(6):837-845.

24. Johnson M. 'What controls aqueous humour outflow resistance?'. Exp Eye Res. 2006;82(4):545-557.

25. Wecker T, Han H, Börner J, Grehn F, Schlunck G. Effects of TGF- $\beta 2$ on cadherins and $\beta$-catenin in human trabecular meshwork cells. Invest Ophthalmol Vis Sci. 2013;54(10):6456-6462.

26. De Groef L, Van Hove I, Dekeyster E, Stalmans I, Moons L. MMPs in the trabecular meshwork: promising targets for future glaucoma therapies? Invest Ophthalmol Vis Sci. 2013;54(12):7756-7763.

27. Zhang M, Maddala R, Rao PV. Novel molecular insights into RhoA GTPase-induced resistance to aqueous humor outflow through the trabecular meshwork. Am J Physiol Cell Physiol. 2008;295(5): C1057-C1070.

28. Tian B, Geiger B, Epstein DL, Kaufman PL. Cytoskeletal involvement in the regulation of aqueous humor outflow. Invest Ophthalmol Vis Sci. 2000;41(3):619-623.

29. Riento K, Ridley AJ. Rocks: multifunctional kinases in cell behaviour. Nat Rev Mol Cell Biol. 2003;4(6):446-456.

30. Liao JK, Seto M, Noma K. Rho kinase (ROCK) inhibitors. J Cardiovasc Pharmacol. 2007;50(1):17-24.

31. Wettschureck N, Offermanns S. Rho/Rho-kinase mediated signaling in physiology and pathophysiology. J Mol Med (Berl). 2002;80(10): 629-638.

32. Fukata Y, Amano M, Kaibuchi K. Rho-Rho-kinase pathway in smooth muscle contraction and cytoskeletal reorganization of non-muscle cells. Trends Pharmacol Sci. 2001;22(1):32-39.

33. Honjo M, Tanihara $\mathrm{H}$, Inatani M, et al. Effects of rho-associated protein kinase inhibitor Y-27632 on intraocular pressure and outflow facility. Invest Ophthalmol Vis Sci. 2001;42(1):137-144.

34. Goldhagen B, Proia AD, Epstein DL, Rao PV. Elevated levels of RhoA in the optic nerve head of human eyes with glaucoma. J Glaucoma. 2012;21(8):530-538.

35. Rao VP, Epstein DL. Rho GTPase/Rho kinase inhibition as a novel target for the treatment of glaucoma. Bio Drugs. 2007;21(3):167-177.

36. Ishizaki T, Maekawa M, Fujisawa K, et al. The small GTP-binding protein Rho binds to and activates a $160 \mathrm{kDa}$ Ser/Thr protein kinase homologous to myotonic dystrophy kinase. EMBO J. 1996;15(8):1885-1893.

37. Leung T, Chen XQ, Manser E, Lim L. The p160 RhoA-binding kinase ROK alpha is a member of a kinase family and is involved in the reorganization of the cytoskeleton. Mol Cell Biol. 1996;16(10):5313-5327.

38. Nakagawa O, Fujisawa K, Ishizaki T, Saito Y, Nakao K, Narumiya S. ROCK-I and ROCK-II, two isoforms of Rho-associated coiled-coil forming protein serine/threonine kinase in mice. FEBS Lett. 1996; 392(2):189-193.

39. Leung T, Manser E, Tan L, Lim L. A novel serine/threonine kinase binding the Ras-related RhoA GTPase which translocates the kinase to peripheral membranes. J Biol Chem. 1995;270(49):29051-29054. 
40. Amano M, Chihara K, Nakamura N, Kaneko T, Matsuura Y, Kaibuchi K. The $\mathrm{COOH}$ terminus of Rho-kinase negatively regulates rho-kinase activity. J Biol Chem. 1999;274(45):32418-32424.

41. Feng J, Ito M, Kureishi Y, et al. Rho-associated kinase of chicken gizzard smooth muscle. J Biol Chem. 1999;274(6):3744-3752.

42. Uehata M, Ishizaki T, Satoh H, et al. Calcium sensitization of smooth muscle mediated by a Rho-associated protein kinase in hypertension. Nature. 1997;389(6654):990-994.

43. Bourguignon LY, Zhu H, Shao L, Zhu D, Chen YW. Rho-kinase (ROK) promotes CD44v(3,8-10)-ankyrin interaction and tumor cell migration in metastatic breast cancer cells. Cell Motil Cytoskeleton. 1999;43(4):269-287.

44. Yoshioka K, Nakamori S, Itoh K. Overexpression of small GTPbinding protein RhoA promotes invasion of tumor cells. Cancer Res. 1999;59(8):2004-2010.

45. Liu X, Hu Y, Filla MS, et al. The effect of C3 transgene expression on actin and cellular adhesions in cultured human trabecular meshwork cells and on outflow facility in organ cultured monkey eyes. Mol Vis. 2005;11:1112-1121.

46. Song J, Deng PF, Stinnett SS, Epstein DL, Rao PV. Effects of cholesterollowering statins on the aqueous humor outflow pathway. Invest Ophthalmol Vis Sci. 2005;46(7):2424-2432.

47. Rao PV, Deng PF, Kumar J, Epstein DL. Modulation of aqueous humor outflow facility by the Rho kinase-specific inhibitor Y-27632. Invest Ophthalmol Vis Sci. 2001;42(5):1029-1037.

48. Sugiyama T, Shibata M, Kajiura S, et al. Effects of fasudil, a Rhoassociated protein kinase inhibitor, on optic nerve head blood flow in rabbits. Invest Ophthalmol Vis Sci. 2011;52(1):64-69.

49. Waki M, Yoshida Y, Oka T, Azuma M. Reduction of intraocular pressure by topical administration of an inhibitor of the Rho-associated protein kinase. Curr Eye Res. 2001;22(6):470-474.

50. Tamura M, Nakao H, Yoshizaki H, et al. Development of specific Rhokinase inhibitors and their clinical application. Biochim Biophys Acta. 2005;1754(1-2):245-252.

51. Nishio M, Fukunaga T, Sugimoto M, et al. The effect of the H-1152P, a potent Rho-associated coiled coil-formed protein kinase inhibitor, in rabbit normal and ocular hypertensive eyes. Curr Eye Res. 2009;34(4):282-286.

52. Fukunaga T, Ikesugi K, Nishio M, et al. The effect of the Rho-associated protein kinase inhibitor, HA-1077, in the rabbit ocular hypertension model induced by water loading. Curr Eye Res. 2009;34(1):42-47.

53. Gupta SK, Agarwal R, Galpalli ND, Srivastava S, Agrawal SS, Saxena R. Comparative efficacy of pilocarpine, timolol and latanoprost in experimental models of glaucoma. Methods Find Exp Clin Pharmacol. 2007;29(10):665-671.

54. Lu Z, Overby DR, Scott PA, Freddo TF, Gong H. The mechanism of increasing outflow facility by rho-kinase inhibition with Y-27632 in bovine eyes. Exp Eye Res. 2008;86(2):271-281.

55. Hahmann C, Schroeter T. Rho-kinase inhibitors as therapeutics: from pan inhibition to isoform selectivity. Cell Mol Life Sci. 2010;67(2): $171-177$.

56. Tokushige H, Inatani M, Nemoto S, et al. Effects of topical administration of y-39983, a selective rho-associated protein kinase inhibitor, on ocular tissues in rabbits and monkeys. Invest Ophthalmol Vis Sci. 2007;48(7):3216-3222.
57. Whitlock NA, Harrison B, Mixon T, et al. Decreased intraocular pressure in mice following either pharmacological or genetic inhibition of ROCK. J Ocul Pharmacol Ther. 2009;25(3):187-194.

58. Tokushige H, Waki M, Takayama Y, Tanihara H. Effects of Y-39983, a selective Rho-associated protein kinase inhibitor, on blood flow in optic nerve head in rabbits and axonal regeneration of retinal ganglion cells in rats. Curr Eye Res. 2011;36(10):964-970.

59. Flammer J, Orgül S, Costa VP, et al. The impact of ocular blood flow in glaucoma. Prog Retin Eye Res. 2002;21(4):359-393.

60. Meyer-ter-Vehn T, Sieprath S, Katzenberger B, Gebhardt S, Grehn F, Schlunck G. Contractility as a prerequisite for TGF-beta-induced myofibroblast transdifferentiation in human tenon fibroblasts. Invest Ophthalmol Vis Sci. 2006;47(11):4895-4904.

61. Honjo M, Tanihara H, Kameda T, Kawaji T, Yoshimura N, Araie M. Potential role of Rho-associated protein kinase inhibitor Y-27632 in glaucoma filtration surgery. Invest Ophthalmol Vis Sci. 2007;48(12):5549-5557.

62. Kitaoka Y, Kitaoka Y, Kumai T, et al. Involvement of RhoA and possible neuroprotective effect of fasudil, a Rho kinase inhibitor, in NMDA-induced neurotoxicity in the rat retina. Brain Res. 2004;1018(1):111-118.

63. Sagawa H, Terasaki H, Nakamura M, et al. A novel ROCK inhibitor, Y-39983, promotes regeneration of crushed axons of retinal ganglion cells into the optic nerve of adult cats. Exp Neurol. 2007;205(1):230-240.

64. Chen YT, Bannister TD, Weiser A, et al. Chroman-3-amides as potent Rho kinase inhibitors. Bioorg Med Chem Lett. 2008;18(24):6406-6409.

65. Stavenger RA, Cui H, Dowdell SE, et al. Discovery of aminofurazanazabenzimidazoles as inhibitors of Rho-kinase with high kinase selectivity and antihypertensive activity. J Med Chem. 2007;50(1):2-5.

66. Tanihara H, Inoue T, Yamamoto T, Kuwayama Y, Abe H, Araie M; K-115 Clinical Study Group. Phase 1 clinical trials of a selective Rho kinase inhibitor, K-115. JAMA Ophthalmol. 2013;131(10):1288-1295.

67. Tanihara H, Inoue T, Yamamoto T, Kuwayama Y, Abe H, Araie M; K-115 Clinical Study Group. Phase 2 randomized clinical study of a Rho kinase inhibitor, K-115, in primary open-angle glaucoma and ocular hypertension. Am J Ophthalmol. 2013;156(4):731-736.

68. Kopczynski C, Lin C-W, deLong M, et al. IOP-lowering efficacy and tolerability of ar-13324, a dual mechanism kinase inhibitor for the treatment of glaucoma. Presented at: Association for Research in Vision and Ophthalmology (ARVO) 2012 Annual Meeting; May 9; 2012; Fort Lauderdale, FL.

69. Zhang K, Zhang L, Weinreb RN. Ophthalmic drug discovery: novel targets and mechanisms for retinal diseases and glaucoma. Nat Rev Drug Discov. 2012;11(7):541-559.

70. Tanihara H, Inatani M, Honjo M, Tokushige H, Azuma J, Araie M. Intraocular pressure-lowering effects and safety of topical administration of a selective ROCK inhibitor, SNJ-1656, in healthy volunteers. Arch Ophthalmol. 2008;126(3):309-315.

71. Chen J, Runyan SA, Robinson MR. Novel ocular antihypertensive compounds in clinical trials. Clin Ophthalmol. 2011:667-677.

72. Kengatharan M, Wirostko B, Umeno H, Hsu H. Pharmaceutical profile of a novel rho kinase (rock) inhibitor ats 907 for reduction of iop in glaucoma. Presented at: Association for Research in Vision and Ophthalmology (ARVO) 2011 Annual Meeting; May 3; 2012; Fort Lauderdale, FL.

73. Arnold JJ, Hansen MS, Gorman GS, et al. The effect of Rho-associated kinase inhibition on the ocular penetration of timolol maleate. Invest Ophthalmol Vis Sci. 2013;54(2):1118-1126.
Clinical Ophthalmology

\section{Publish your work in this journal}

Clinical Ophthalmology is an international, peer-reviewed journal covering all subspecialties within ophthalmology. Key topics include: Optometry; Visual science; Pharmacology and drug therapy in eye diseases; Basic Sciences; Primary and Secondary eye care; Patient Safety and Quality of Care Improvements. This journal is indexed on Submit your manuscript here: http://www.dovepress.com/clinical-ophthalmology-journal
Dovepress

PubMed Central and CAS, and is the official journal of The Society of Clinical Ophthalmology (SCO). The manuscript management system is completely online and includes a very quick and fair peer-review system, which is all easy to use. Visit http://www.dovepress.com/ testimonials.php to read real quotes from published authors. 